\title{
Experimental and numerical analyses on thermal performance of different typologies of PCMs integrated in the roof space
}

\author{
Elarga, Hagar; Fantucci, Stefano; Serra, Valentina; Zecchin, Roberto; Benini, Ernesto
}

Published in:

Energy and Buildings

Link to article, DOI:

10.1016/j.enbuild.2017.06.038

Publication date:

2017

Document Version

Peer reviewed version

Link back to DTU Orbit

Citation (APA):

Elarga, H., Fantucci, S., Serra, V., Zecchin, R., \& Benini, E. (2017). Experimental and numerical analyses on thermal performance of different typologies of PCMs integrated in the roof space. Energy and Buildings, 150, 546-557. https://doi.org/10.1016/j.enbuild.2017.06.038

\section{General rights}

Copyright and moral rights for the publications made accessible in the public portal are retained by the authors and/or other copyright owners and it is a condition of accessing publications that users recognise and abide by the legal requirements associated with these rights.

- Users may download and print one copy of any publication from the public portal for the purpose of private study or research.

- You may not further distribute the material or use it for any profit-making activity or commercial gain

- You may freely distribute the URL identifying the publication in the public portal 

integrated in the roof space

${ }^{1}$ International Centre for Indoor Environment and Energy ICIEE,Department of Civil Engineering, Technical University of Denmark Kgs. Lyngby, 2800,Denmark

${ }^{2}$ TEBE Research Group, Department of Energy, Politecnico di Torino, Corso Duca degli Abruzzi 24, 10129 Torino, 9 Italy

${ }^{3}$ Manens-Tifs Sp.A., Corso Stati Uniti 56, 35127, Padova, Italy

${ }^{4}$ Department of Industrial Engineering, University of Padua, Via Venezia 1, 35131, Padova, Italy

*Corresponding author: Hagar Elarga

E-mail address: hagel@byg.dtu.dk (H.Elarga)

\section{ABSTRACT}

The study investigates the thermal performances of Phase Change Materials (PCM) integrated in a roof space to be used as a residential attic in Torino, Italy. Three different solutions were applied to a roof continuously monitored under summer climatic conditions. The roof was divided into three portions, one, the bare roof, representing the reference case without PCMs, the other two integrating two PCM's typologies with different melting/solidification temperatures range. A numerical model was furthermore developed implementing the equivalent capacitance numerical method to describe the substance phase transition and the measured data set were used for its validation. The study demonstrates that PCMenhanced components are a promising solution toward a higher thermal performance efficiency in roof attic spaces during summer season. Experimental results showed a reduction of the ongoing heat peak load between 13\% and 59\% depending on the PCM typology, highlighting that to reach the expected performance the proper PCM type should be carefully selected.

Keywords: PCM; Roof attic space; RC model; Numerical simulations; Experimental analysis

\section{Introduction}

The Climate change is jeopardizing living sustainability on the planet. This change is affecting different life aspects such as water resources, coastal zone, marine systems and energy consumption[1]. Concerning the latter aspect, the building sector is estimated to be $\sim 40 \%$ from the total energy consumption in EU. Space heating and cooling energy demands from the building envelope represent about $47 \%$ of the total energy demands within a typical residential/commercial building [2]. Generally, in residential buildings, the surface that has the largest exposure to the outdoor environment and, consequently, most subjected to the climate change is represented by the roof. Indeed the U.S. Department of energy estimate that the roof attic space alone are responsible for $12 \%-14 \%$ of the energy required for space heating and cooling in U.S.[3]. This aspect assumes relevant importance since the conversion of roof attic in habitable spaces represents one of the principal interventions to increase the density of urban area without consuming 
new soil. In Italy, several policies at regional level have promoted this retrofit action, which presents an added value to other conventional interventions aimed at refurbishing buildings envelope and building services [4]. A key issue in the conversion of attic space is represented by the thermal refurbishment of the roof, which presents, with respect to a typical dwelling unit a larger exposed area, responsible of high thermal gains/losses respectively in summer and winter [5]. As far as the energy retrofit of an existing roof, the addition of new insulation layers raises particular issues which have to be duly taken into account as the height reduction of the internal space and the structural load increase on the existing roof. In the latest years, a number of technologies have been developed to improve winter and summer behavior of roofs components and overcome these limitations through reduced thickness and weight of super insulating materials [6][7][8], radiant heat barriers [9][10], ventilated air cavity [11][12][13], and cool materials [14][15][16]. A different approach, so far not so investigated in this kind of application, is to improve the dynamic thermal properties of the roof assembly by implementing Phase Change Materials (PCMs) [17],[18]. These are characterized by high thermal capacitance within their transition phase, stabilizing the indoor surface temperatures and delaying the thermal wave during the night hours, when coupling this strategy with passive cooling strategies (e.g. night ventilation) the heat stored during daytime can be efficiently removed (discharging phase).

\subsection{PCMs implementation in building components}

PCMs in buildings can be integrated as passive or active systems [19]. Several case studies demonstrates that PCMs should be incorporated into walls, roofs, windows, thermal insulation materials and furniture [20]. Kuznik et al. [21] investigated a renovation project in the south of France using PCM wallboards. The analysis was carried out by testing two rooms renovated with and without PCMs, they concluded that the PCMs increased the indoor thermal comfort, but for several days the applied PCM appeared unable to use its latent heat storage capacity due to the incomplete discharge overnight. This fact has highlighted the importance of the PCM system design to allow for the complete charge and discharge processes. Xu et al. [22] investigated the thermal performance of a PCM floor system in passive solar buildings. The study highlighted that the performances are affected by several factors such as layer thickness, melting temperature, thermal conductivity and latent heat of fusion of PCMs, choice of covering material and the presence of air gap between PCM and covering material. The results showed that the thickness of PCM should not be greater than 20 $\mathrm{mm}$ and the latent heat of fusion and thermal conductivity of PCM should respectively exceed $120 \mathrm{~kJ} / \mathrm{kg}$ and $0.5 \mathrm{~W} /(\mathrm{m}$ K). In [23] the performance of a plaster embedding PCM, applied to the internal side of the walls was investigated, from the embodied energy and operational energy point of view, concluding that for the analyzed case study (a simple rectangular room located in Italy), the high embodied energy of the PCM plaster was not counter balanced by the benefits in terms of operational energy reduction (nevertheless the improvement of comfort conditions are not considered in the analysis). The performance of PCMs integrated in roofs are investigated by several authors. An experimental investigation on a roof coupled with PCMs and cool materials is presented in [24], where a PCM mixture encapsulated in polyethylene pipes placed in the external side of the roof (under the mortar levelling layer). Three test rooms were monitored in order to compare the influence of PCMs layer and the coupling of PCM and cool roof technology on the same roof section without PCM. The results are promising, showing an average reduction of the indoor roof peak temperature, respectively of $0.58^{\circ} \mathrm{C}$ for the PCM embedded roof and $0.84^{\circ} \mathrm{C}$ for the $\mathrm{PCM}$ embedded cool roof. The application of PCM in polyurethane roof membranes was investigated in [25]. The results of the in-lab characterization, demonstrate that the proposed prototype of waterproof membrane could represent an effective passive cooling solution, combining the effect of cool roofs and latent heat capacity due to the presence of PCM. Furthermore the application of PCM in walls and roof was simulated in [26], implementing Fanger model to control the HVAC 
system. Results highlight the potential of PCM in enhancing the energy efficiency of buildings. In particular, PCM 10 $\mathrm{mm}$ thick and melting temperature of $27^{\circ} \mathrm{C}$ allows the highest annual energy savings with the shorter payback period.

In this paper, experimental and numerical analyses were carried out on an existing residential building roof integrated with PCMs, with the aims to:

- Evaluate the thermal improvements due to PCMs integration in the summer season;

- Investigate the effects of the PCMs transition temperature on the roof global performance;

- Develop and validate a numerical model to be used to extend the analyses to other roofs typologies and locations.

\section{Experimental analysis of PCMs integrated in a roof component}

\subsection{Case study description}

The experimental campaign was carried out during summer 2016 in San Francesco al Campo - Turin (Italy 45.23 N, 7.66 E). The selected case study is represented by an attic space of a residential building under refurbishment. The existing roof is a timber-frame double pitched roof, with clay roof tiles as external covering. The roof was divided in three different portions in which different roof assemblies were installed. The Configuration A (reference case) consists of four layers (roof clay tiles, air permeable gap, XPS insulation and gypsum board). In order to analyse the influence of the PCM integration in building components and understand the thermal trends of this technology, two different PCM types were used, RT28HC and RT35 [27] (Table 1), respectively installed in configurations B and C. The configurations are composed by hollow polycarbonate panels filled with PCM (already adopted in [28] (Fig.1) and were installed between the gypsum board and the XPS layers (Fig.2). Technical specifications of roof sections are summarised in Table 2.

\subsection{Measurement methodology}

The thermal performance assessment of the three configurations through experimental data analyses has been divided into two tracks:

- The comparison of indoor surface temperatures and heat fluxes between Config. A vs Config. B and Config. A vs Config. C;

- The comparison of the PCMs surface temperature profiles of Config. B vs Config. C;

The monitored roof sections are South South-West exposed with a slope of $28^{\circ}$. During the monitoring period, the indoor space (floor area $\sim 110 \mathrm{~m}^{2}$ ) was in free-floating regime with high ventilation rate. The air exchanges were guaranteed by:

- The infiltration through the roof tiles;

- The presence of an open window $\left(\sim 1.25 \mathrm{~m}^{2}\right)$.

The monitoring system aimed at assessing the surface temperatures and the energy transmission variation due to the presence of PCMs was composed by 20 type-T thermocouples, 3 heat flux meter sensors and 1 pyranometer connected to a data logger DT600 with channel expansion module. The measurements were carried out with a time interval of 5 minutes. 
The outdoor boundary conditions (air temperature, relative humidity, wind speed and direction) were continuously monitored by means of a weather station installed above the roof-top (Fig. 3). Moreover, the second class pyranometer LP02 (calibration uncertainty $\leq 1.8 \%$ ) was installed for the measurement of the incident global solar radiation (Fig. 3). Temperatures across the roof sections were measured by means of type-T thermocouples (nominal accuracy $\pm 0.25 \mathrm{~K}$ ) (Fig. 4). Moreover, the heat fluxes were measured by means of HFP01 heat flux sensors (measurement uncertainty \pm $5 \%$ ) placed in the indoor side (Fig.5).

In order to avoid the influence of the radiation heat exchange between the roof and the indoor surrounding surfaces (floor, walls), the indoor surfaces of the samples were covered with a radiant barrier (aluminium shine foil). The roof clay tiles are characterised by high air permeability, due to the joints of the tiles allowing air exchanges between the cavity and the outside. A characterization of the infiltration rate in the cavity below the roof tiles was carried out by means of the tracer-gas technique. To this purpose, a small scale sealed room was built under the roof portion without the insulation layers (Fig.6). The measurements were repeated several times during the monitoring days and an average infiltration rate $\sim 3.3\left(\mathrm{~m}^{3} / \mathrm{h}\right) / \mathrm{m}^{2}$ was estimated. It is important to remark that this infiltration rate value is strictly dependent by the wind speed; the measurements were carried out with low wind speed $(\mathrm{v}<7 \mathrm{~km} / \mathrm{h})$ in line with the site average values.

\subsection{Experimental results}

The experimental results were used to compare the thermal performance of the different roof configurations and to validate a numerical model. One week of experimental results (from $13^{\text {th }}$ to $20^{\text {th }}$ August) representative of the summer conditions is reported in Fig.7.

In the monitored week, the outdoor temperature (black line) was between $\sim 16^{\circ} \mathrm{C}$ (minimum night temperature) and $\sim 32^{\circ} \mathrm{C}$ (maximum daily temperature), while the indoor temperatures were between $\sim 20^{\circ} \mathrm{C}$ and $\sim 33^{\circ} \mathrm{C}$. The wind speed (black points) was in line with the average conditions of Turin (IT) wind zone, which is generally characterized by low wind velocity $(\mathrm{v}<10 \mathrm{~km} / \mathrm{h})$ except for the afternoon of $16^{\text {th }}$ August $(\mathrm{v}>15 \mathrm{~km} / \mathrm{h})$ due to the presence of a summer storm.

During the sunny days $\left(13^{\text {th }}, 14^{\text {th }}\right.$ and $17^{\text {th }}$ August $)$ the incident global solar radiation reached a peak of $\sim 1000 \mathrm{Wm}^{-2}$ at 2:00 pm.

\subsubsection{Indoor surface temperatures and heat fluxes}

A comparison between the indoor surface temperature and heat fluxes between the reference configuration A (no PCMs) and configuration B (PCM RT28-HC) is presented in Fig. 8 while a comparison between A and C (PCMs RT35) is reported in Fig. 9. The indoor surface temperatures of the roof $\left(\mathrm{T}_{\mathrm{si}}\right)$ are plotted in black continuous line for configuration A and grey continuous lines for configurations B and C with PCM, while the heat fluxes crossing the roof are plotted in dashed lines.

In Fig. 10, the thermal performance profiles (i.e inner surface temperature and heat flux) for the three configurations on August $17^{\text {th }}$ are illustrated. The reference configuration A (black line) presents the highest surface temperature during daytime $\left(37.3^{\circ} \mathrm{C}\right)$, reaching its peak between 4:00 pm and 5:00 pm. These temperature profile is followed by configuration C (PCMs-RT35) reaching $35.2^{\circ} \mathrm{C}$ (grey line) and B (RT28HC) with $29.1^{\circ} \mathrm{C}$ (dashed grey line) demonstrating the capability of PCM layers to reduce the indoor surface peak temperatures during daytime. As 
expected; during the night and in the early morning, configuration A shows lower temperatures due to the lack of dynamic thermal inertia, i.e. heat charging and discharging capability of the PCM layer in the latter two cases.

In Table 3 the results reported in Fig. 10, are summarized highlighting the peak difference among the three configurations in terms of indoor surface temperatures $T_{s i}$, as far as the heat fluxes and energy crossing the roof are concerned, while in Table 4 the ongoing energy loads and outgoing energy removed from the indoor space are compared for different time intervals during the day, highlighting that:

- During the night and in early morning (00:00 am - 8:00 am) configuration B is characterized by the highest value of ongoing energy $\left(\sim 100 \mathrm{Wh} / \mathrm{m}^{2}\right)$. This is due to its higher temperature if compared to configuration $\mathrm{C}$, while the reference configuration A, without PCMs, is only subject to heat losses.

- In the morning (8:00 am - 12:00 am) configuration $\mathrm{C}$ is characterized by high value of heat losses $(\sim 48$ $\mathrm{Wh} / \mathrm{m}^{2}$ ), while configuration B presents both energy loads and losses with a positive energy balance of 11.7 $\mathrm{Wh} / \mathrm{m}^{2}$.

- In the afternoon (12:00 am - 4:00 pm) both configurations B and C present a good capability in removing the heat from the indoor space with 40.0 and $64.6 \mathrm{Wh} / \mathrm{m}^{2}$ of energy losses respectively, while Configuration A is characterized by $\sim 17 \mathrm{Wh} / \mathrm{m}^{2}$ of energy loss;

- In the evening (4:00 pm - 8:00 pm) configuration B continues to remove heat from the indoor space (working in its melting phase), while configuration $\mathrm{C}$ is characterized by higher temperature and lower value of heat loads (solid phase);

- Later in the evening (8:00 pm - 00:00 am) configuration C presents high value of heat load $\left(\sim 49 \mathrm{Wh} / \mathrm{m}^{2}\right)$, while in both the other configurations A and B the heat loads are significantly lower (respectively $\sim 17$ and $\sim 11$ $\left.\mathrm{Wh} / \mathrm{m}^{2}\right)$.

\subsubsection{Surface temperature profiles of the PCM layer}

To highlight the importance of PCM type selection, the temperature profiles of the inner PCM layer for configuration B vs configuration $\mathrm{C}$ is shown in Fig. 11. Configuration $\mathrm{B}$ has a flattered surface temperature between $26^{\circ} \mathrm{C}$ and $30^{\circ} \mathrm{C}$, which indicates that the substance is in its transition phase with the higher values of equivalent specific heat capacity. Until the approaching of mid-day (time interval which is defined by higher values of the solar radiation intensity and external air temperature values), the PCM (RT28-HC) temperature has increased slightly, however it did not exceed the upper limit of phase change range to totally turned to the liquid phase. On the other hand; in configuration C (RT 35), the PCM mostly is in solid state, since the melting starts at $34 \square \mathrm{C}$, and accordingly the specific heat capacity is in its minimum value of $2 \mathrm{~kJ} / \mathrm{kg} \mathrm{K}$.

To conclude; PCM RT28-HC shows a better exploitation of the phase transition during the day, allowing to contain the heat gains and accordingly to improve the overall thermal behavior during daytime. Nevertheless, during the night PCM RT28-HC shows higher values of heat loads released to the indoor space if compared to RT35. This behavior has to be carefully taken into account during the design phase according to the final use of the indoor space and users' occupancy profiles.

\section{Development of a numerical model}


A finite difference model was developed to estimate the heat transfer mechanism in the monitored case studies and to build a theoretical basis for better explaining the measured data. In the numerical model the solution domain is defined by a number of grid points in which the derived linear equations form a matrix system as shown in Eq. (1), where A is the matrix of coefficients, $\mathrm{X}$ is the vector of unknowns and $\mathrm{B}$ is the column vector of known terms. The system is solved by inverting the matrix to obtain the temperature values $\mathrm{X}$.

$$
[A]\{X\}=\{B\}
$$

200

According to nodes energy balance, the numerical solving scheme starts from the initial conditions of temperatures till the nodal temperature $T_{n, i}$ is obtained. Nevertheless, there is an iterative cycle which is of key importance in the code. A temperature correction scheme is followed by saving the solution of the matrix in the previous iteration and solving the system until the convergence criteria is reached (difference between the current temperature and the values of the previous time step $\leq 0.5^{\circ} \mathrm{C}$ ). The code thus saves and starts a new time step implementing the previously solved time step nodal temperatures values as the initial condition (Fig.12).

\subsection{Numerical simulation of PCMs}

There are several methods to take into account the transient physical state of PCM, such as enthalpy method or the equivalent heat capacity method, which was implemented in the present study. The technique has been proposed in [29] and [30] and it is based on the linear approximation of the heat flux between PCM nodes. The grid was numerically solved using the implicit fixed scheme that employs linearization, initial conditions and adopts an iterative procedure until convergence is obtained Error! Reference source not found.[31].

For each node, the $C_{P C M}^{*}$ as a function of $\mathrm{T}_{\mathrm{PCM}}$ was evaluated using a continuous linear function determined by the physical properties of the PCM $\left(T_{P C M, i n}, T_{P C M, m}, h_{P C M}, C_{P C M, s}, C_{P C M, l}\right)$ which are provided by the manufacturer [27]. The linear employed equations indicated in Fig.13 and listed from Eq.(2) to Eq.(5) allow to determine the specific heat capacity of PCM as a function of $T_{P C M}$. Furthermore, $C_{P C M, m}^{*}$, which is the maximum specific heat capacity of the considered PCM, is defined by Eq.(6).

Value of specific heat capacity

$$
\begin{array}{lc}
C_{P C M}^{*}\left(T_{P C M}\right)=C_{P C M, S} & T_{P C M} \leq T_{P C M, s} \\
C_{P C M}^{*}\left(T_{P C M}\right)=C_{P C M, s}+\frac{C_{P C M, m}^{*}-C_{P C M, s}}{T_{P C M, m}-T_{P C M, s}}\left(T_{P C M}-T_{P C M, S}\right) & T_{P C M, s}<T_{P C M} \leq T_{P C M, m} \\
C_{P C M}^{*}\left(T_{P C M}\right)=C_{P C M, l}+\frac{C_{P C M, m}^{*}-C_{P C M, l}}{T_{P C M, m}-T_{P C M, l}}\left(T_{P C M}-T_{P C M, l}\right) & T_{P C M, m}>T_{P C M}<T_{P C M, l} \\
C_{P C M}^{*}\left(T_{P C M}\right)=C_{P C M, l} & T_{P C M} \geq T_{P C M, l} \\
C_{P C M, m}^{*}=\frac{T_{p c m, s-T_{p c m, m}}}{\Delta T_{h}} \cdot C_{P C M, s}+\frac{T_{p c m, m-} T_{p c m, l}}{\Delta T_{h}} \cdot C_{P C M, l}+\frac{2 h_{p c m}}{\Delta T_{h}}
\end{array}
$$


The thermal properties of each node inserted in the PCM layer, (e.g. specific heat capacity and density) are evaluated as a function of the previous time step temperature input $T_{P}{ }^{\circ}$. In the present study $1 \mathrm{~cm}$ thickness PCM layer is discretised into three homogenous layers, therefore the energy balance equation (Eq.7) of each PCM node is:

$$
\rho_{p} C_{p}{ }^{*}(T) \frac{T_{P}-T_{P}^{\circ}}{\Delta_{\tau}}=\frac{K_{p}}{\Delta x}\left(T_{P-1}-T_{P}\right)+\frac{K_{P}}{\Delta x}\left(T_{P+1}-T_{P}\right)
$$

221

\subsection{RC modelling}

The thermal resistance is defined as the ratio of the temperature difference between two thermal nodes, $\left(T_{i}-T_{i+1}\right)$ and the heat transfer $Q$ that flows between the two thermal nodes. This is analogous to Ohm's law, in which the electrical resistance is defined as the ratio between the voltage drop across a resistor and its current flow. Thermal resistances $R_{k}$, $R_{c}$ and $R_{r a d}$ represents respectively conduction, convection, and radiation heat transfer between the wall layers and they are determined respectively through Eq. (8), (9), and (10).

$$
\begin{aligned}
& \mathrm{R}_{\mathrm{k}}=\frac{\mathrm{x}}{\lambda} \\
& \mathrm{R}_{\mathrm{C}}=\frac{1}{\mathrm{~h}_{\mathrm{c}}} \\
& \mathrm{R}_{\mathrm{rad}}=\frac{1}{\mathrm{~h}_{\mathrm{r}}}
\end{aligned}
$$

The convection heat transfer coefficients have been evaluated by different empirical laws:

- For the outdoor surface the McAdams correlation [32] was adopted Eq. (11);

$h_{c}=5.62+3.9 v$

- For the free convection in the natural ventilated air cavity [33]:

$h_{c}=1.52 \cdot|\Delta T|^{1 / 3}$

Where $\Delta T$ is the maximum difference value of the roof tile layer and the air cavity or the XPS layer and the air cavity.

- For the indoor layer, the convection heat transfer is considered free convection, since there is no serving HVAC system, and is evaluated by Eq. (13) [34]:

$$
h_{c}=\left\{\left[1.5 \cdot\left|\frac{\Delta T}{H}\right|^{0.25}\right]^{6}+\left[1.23 \cdot(\Delta T)^{0.33}\right]^{6}\right\}^{1 / 6}
$$

Where $\Delta T$ is the difference between the indoor air temperature and the indoor surface temperature, while $H$ is the floor height.

For the radiation heat exchange Eq. (14) and (15) was used [35].

$$
R_{\text {rad }}=\frac{\left[\frac{1}{\epsilon_{1}}+\frac{1}{\epsilon_{2}}-1\right]}{\left[4 . \sigma \cdot T_{\text {avg }}^{3}\right]}
$$


And hence:

$$
h_{r}=\frac{4 \sigma\left(T_{a v g}\right)^{3}}{\left(\frac{1}{\varepsilon_{1}}+\frac{1}{\varepsilon_{2}}-1\right)}
$$

Where: $T_{\text {avg }}$ is the average temperature of the two opposite surfaces, which has been evaluated as function of temperature previous time step values.

\subsection{Numerical Model A (without PCM)}

Model A (Config. A) is considered as the comparison reference case (Fig.14a). The specific heat capacity of the roof tiles and gypsum board are considerably higher than the XPS layer, hence each layer is represented in the RC scheme (Fig.14b) by two conductance resistances and a capacitance. The mathematical equations for the eight nodes are classified in equations from (16) to (24).

- For nodes 1 and 8, the heat transfer through the outer and inner layers of the roof surface is described by two thermal resistances, the convection heat transfer with the ambient conditions and the conduction transfer within the layer itself.

$$
\begin{aligned}
& T_{1}\left(-\frac{1}{R_{c o}}-\frac{1}{R_{k B}}\right)+T_{2}\left(\frac{1}{R_{k B}}\right)=-\frac{1}{R_{c o}} T_{e}-I \cdot \alpha_{B} \\
& T_{8}\left(-\frac{1}{R_{c i}}-\frac{1}{R_{k-g y p}}\right)+T_{7}\left(\frac{1}{R_{k-g y p}}\right)=-\frac{1}{R_{c i}} T_{i}
\end{aligned}
$$

- For nodes 2 and 7, the energy have included the thermal storage influence and nodal temperature changes with the time. Taking into consideration that $T_{n}{ }^{\circ}$ is the node temperature evaluated at the previous time step.

$$
\begin{aligned}
& T_{1}\left(\frac{1}{R_{k B}}\right)+T_{2}\left(\frac{-2}{R_{k B}}-\frac{\rho \Delta x_{b r} c_{b r}}{\Delta \tau}\right)+T_{3}\left(\frac{1}{R_{k B}}\right)=-\frac{\rho \Delta x_{b r} c_{b r}}{\Delta \tau} T_{2}^{\circ} \\
& T_{6}\left(\frac{1}{R_{k-g y p}}\right)+T_{7}\left(\frac{-2}{R_{k g y p}}-\frac{\rho \Delta x_{g y p} c_{g y p}}{\Delta \tau}\right)+T_{8}\left(\frac{1}{R_{k-g y p}}\right)=-\frac{\rho \Delta x_{g y p} c_{g y p}}{\Delta \tau} T_{7}^{\circ}
\end{aligned}
$$

- The radiation heat exchange coefficient $h_{r}$ between nodes 3 and 5 is considered as a function in nodal temperatures Eq. (20). The average temperature of the two opposed surface is evaluated in the previous time step.

$T_{\text {avg }}=\frac{T_{3}^{\circ}+T_{5}^{\circ}}{2}$

- The convection heat transfer within the air cavity and the conduction heat transfer through the element are showed in the energy balance Eq. (21) and (22) 


$$
\begin{aligned}
& T_{2}\left(\frac{1}{R_{k B}}\right)+T_{3}\left(\frac{-1}{R_{k B}}-\frac{1}{R_{c}}-\frac{1}{R_{r}}\right)+T_{4}\left(\frac{1}{R_{c}}\right)+T_{5}\left(\frac{1}{R_{r}}\right)=0 \\
& T_{3}\left(\frac{1}{R_{r}}\right)+T_{4}\left(\frac{1}{R_{c}}\right)+T_{5}\left(\frac{-1}{R_{k-x p s}}-\frac{1}{R_{c}}-\frac{1}{R_{r}}\right)+T_{6}\left(\frac{1}{R_{k-x p s}}\right)=0
\end{aligned}
$$

- In Node 4, the infiltration airflow rate $m_{v}$ was estimated by the experimental measurements see Section 2.1 . Accordingly, the air cavity node energy balance is:

$$
T_{3}\left(\frac{1}{R_{c}}\right)+T_{4}\left(-\frac{2}{R_{c}}-m_{v} C\right)+T_{5}\left(\frac{1}{R_{c}}\right)=-m_{v} C T_{v}
$$

- In Node 6, the energy balance of the interaction node between two layers of the XPS and gypsum board is:

$$
T_{5}\left(\frac{1}{R_{k-x p s}}\right)+T_{6}\left(\frac{-1}{R_{k-x p s}}-\frac{1}{R_{k-g y p}}\right)+T_{7}\left(\frac{1}{R_{k-g y p}}\right)=0
$$

\subsection{Numerical Models B and C integrating PCM}

The schematic description of cases B and C (Fig.15a) is similar to case A apart from the PCM layer analysis. One of the study focal points is to investigate the influence of PCM melting and specific heat capacity values on the overall energy balance. The RC model is illustrated in Fig.15b.

Each homogenous sub-layer (from the three nodes representing the PCM layer) is represented by a conductive resistance and a capacitance. For the sake of brevity, the resulting thermal balance equation Eq. (24) is shown for node (8)

$$
\left(\frac{k_{p}}{x_{p}}\right)_{p 7}+\left(-2 \frac{k_{p}}{x_{p}}-\frac{\rho \cdot x_{p} \cdot c_{p 2}}{\Delta \tau}\right) T_{p 8}+\left(\frac{k_{p}}{x_{p}}\right)_{p 9}=-I \cdot\left(\frac{a_{p 2}}{2}\right)-\left(\frac{\rho \cdot x_{p} \cdot c_{p 2}}{\Delta \tau}\right) \cdot\left(T_{p 8}\right)^{\tau-1}
$$

\subsection{Model validation}

For the determination of the numerical model's reliability, the Root Mean Square Error (RMSE $\left[{ }^{\circ} \mathrm{C}\right]$ ) calculated according to Eq. (26) were used:

$$
R M S E=\sqrt{n^{-1} \cdot \sum_{j=1}^{n}\left(s_{j}-e_{j}\right)^{2}}
$$

Where: $s_{j}$ and $e_{j}$ are respectively the predicted values and measured values for times $j$, and $n$ is the number of values of the series.

For the validation of the numerical models, a comparison between the measured values of the inner and outer roof surfaces was carried out. Furthermore, the measured set of data has been analyzed to optimize the implementation decision of PCM in buildings and the influence of the PCM material proper selection.

\subsubsection{Numerical results and model validation}


Among the seven monitored days presented in section 2.3, August $16^{\text {th }}$ was selected for the model validation because it is characterized by different weather conditions during the same day (including summer storm and rain), so as the numerical model response could be evaluated under variable climatic boundary conditions. The comparison between numerical and experimental results is plotted in Fig. 16, 17 and 18 respectively for Configurations A, B and C for the outdoor and indoor surface temperatures. For the determination of the indoor surface temperature, it is to underline that indoor zone is not thermally controlled, and windows are kept open day and night.

The RMSE have been estimated for all experimentally investigated surfaces, and temperatures nodes have been ordered according to Figures 16-18. Values are summarized in Table 6. RMSE results in a range between $0.4{ }^{\circ} \mathrm{C}$ (inner surface) and $4{ }^{\circ} \mathrm{C}$ (outer roof tiles surface). The difference appearing in the outdoor surface temperature during night hours is justified considering that the numerical model neglects the radiation heat exchange between the outer surface with the sky and adjacent surfaces. Moreover as explained in section 2.3, between 3:00 and 5:00 pm, a summer storm occurred, which explains the reason of the mismatch between measured and predicted values, in fact the numerical model has neglected the effect of roof tiles cooling caused by rain water. On the other hand, some parameters controlling the heat transfer in buildings are complex to be predicted (e.g. surface heat transfer coefficient), for all these reasons, the numerical models accuracy is considered acceptable, especially because the difference between the experimental and calculated results have been decreased in the peak time and the two temperature profiles were matched, as shown in Figures (17) and (18).

\section{Conclusions}

In this study, a roof-mounted PCM filled panels with different melting temperature were monitored and compared with a reference roof without PCM layer. The analyses focused on the temperature and heat flux peaks reduction, highlighting that the presence of PCM layers obtains:

- A reduction in the indoor surface peak temperature of $\sim 2.2^{\circ} \mathrm{C}$ and $\sim 8.2^{\circ} \mathrm{C}$ respectively for the RT35 and the RT28HC configurations;

These results demonstrate the importance of the proper PCM selection. In fact PCM which mainly works in its transition phase (RT28HC) shows higher capability to reduce the heat load in the below attic space during the hottest hours of the day. Meanwhile a more evident ceiling surface temperature reduction should contribute to the improvement of the indoor comfort condition.

The analysis on the energy flows highlights that both PCM configurations determines heat loads released to the indoor environment during their discharging phase. These results underline the importance of coupling PCM with passive night cooling strategies (e.g. night ventilation) to guarantee the efficacy of the PCM in reducing the daily heat loads. Moreover, a numerical RC model implementing the PCM behavior was developed. The model was validated through a comparison with the measured data, showing a RMSE between $0.4^{\circ} \mathrm{C}$ (indoor surface temperature) and $4^{\circ} \mathrm{C}$ (outdoor surface temperature), according to the magnitude of the temperature variation during the day. The whole year measurements on the presented roof are still in progress and a more complete picture of the influence of PCMs layer on the overall energy balance will be thus possible. Implementing PCMs in roof attic is a promising solution to enforce; peak load savings with a range of $\sim 13$ to $\sim 59 \%$ and to take advantage of all unused areas in residential houses keeping acceptable thermal conditions. However, it is important to take into consideration that it may not always be a suitable 
318 efficient application for all climatic conditions. Exploratory numerical simulations have to be carried out during the early 319 design stages to ensure the benefits achievable by using PCM.

320 The developed numerical model needs further improvements and modifications to expand the results on urban scale level.

321 Future work plan is focusing on coupling TRNSYS software to the1-D model in order to investigate the behavior of building components implementing PCMs; in particular, the thermal optimization in different climatic conditions for 323 different roofs assemblies. 


$\begin{array}{ll}\text { PCM } & \text { Phase Change Material } \\ \text { XPS } & \text { Extruded Polystyrene } \\ \text { TES } & \text { Thermal Energy Storage } \\ \text { HVAC } & \text { Heating Ventilation and Air Conditioning } \\ \text { RMSE } & \text { Root Mean Square Error } \\ \mathrm{SF}_{6} & \text { Sulphur Hexafluoride }\end{array}$




\section{Greek symbols}

$\alpha$

V

$\varepsilon$

$\rho$

$\sigma$

$\Delta T_{h}$

$\tau$.

$\beta$

$\Phi$

$\lambda$

331

332

1

$\mathrm{h}$

m

$\mathrm{P}$

r

i

o

333

334
Short wave solar absorption coefficient

$(-)$

Wind velocity

$(\mathrm{m} / \mathrm{s})$

Long wave radiation emissivity

$(-)$

Air density

$\mathrm{kg} / \mathrm{m}^{3}$

Stefan-Boltzmann constant, $\left(5.67 \times 10^{-8}\right)$

$\mathrm{W} /\left(\mathrm{m}^{2} \mathrm{~K}^{4}\right)$

Temperature range of phase change

${ }^{\circ} \mathrm{C}$

Time step

$\mathrm{S}$

Liquid fraction

$\%$

Heat flux

$\mathrm{W} \mathrm{m}^{-2}$

Thermal conductivity

$\mathrm{W} / \mathrm{mK}$

Solid state

Liquid state

PCM Melting/solidification temperature range difference

Melting peak

PCM node

Reference

Indoor

Outdoor

Previous time step

Equivalent 
[1] IPCC, CLIMATE CHANGE 2001: impacts, adaptation and vulnerability, Work.Gr. II Impacts Adapt. vulnerability, 2001, p. 10.

341 [2] EPBD recast, Directive 2010/31/EU of the European Parliament and of Council of 19 May 2010 on the energy performance of buildings (recast). Official Journal of the European Union; 2010

343 [3] U.S. Department of Energy, 2011 Buildings Energy Data Book, 2012, p. 286.

344 [4] Consiglio regionale del Piemonte - Regional law $6^{\text {th }}$ august 2008 n.21, Norme per il recupero del sottotetto a fini 345 abitativi.

$346[5]$ L. Bianco, R. Pollo, V. Serra, Wood fiber vs synthetic thermal insulation for roofs energy retrofit: a case study in 347 Turin, Italy, Energy Procedia (in Press).

348 [6] A. Lorenzati, S. Fantucci, A. Capozzoli, M. Perino, Coupling VIPs and ABPs: Assessment of Overall Thermal 349 Performance in Building Wall Insulation, Energy Procedia, Volume 78 (2015), 2760-2765.

350 http://dx.doi.org/10.1016/j.egypro.2015.11.620.

351 [7] F. Isaia, S. Fantucci, A. Capozzoli, M. Perino, Vacuum Insulation Panels: Thermal Bridging Effects and Energy 352 Performance in Real Building Applications, Energy Procedia, 83 (2015), 269-

353 278, http://dx.doi.org/10.1016/j.egypro.2015.12.181.F.

354 [8] Isaia, S. Fantucci, A. Capozzoli, M.Perino, Thermal bridges in vacuum insulation panels at building scale, 355 Proceedings of the Institution of Civil Engineers - Engineering Sustainability 170-1 (2017), 47-60. 356 http://dx.doi.org/10.1680/jensu.15.00057.

357 [9] K.S. Ong, Temperature reduction in attic and ceiling via insulation of several passive roof designs, Energy 358 Conversion and Management 52-6 (2011), 2405-2411. http://dx.doi.org/10.1016/j.enconman.2010.12.044.

359 [10] A.D. Fontaninia, K. M. Pr'Outa,1, J. Kosnyb, B.Ganapathy subramaniana, Exploring future climate trends on the 360 thermal performance of attics : Part 1 - Standard roofs, Energy and Buildings 129 (2016) 32-45.

361 [11] A. Gagliano, F. Patania, F. Nocera, A. Ferlito, A. Galesi, Thermal performance of ventilated roofs during 362 summer period, Energy and Buildings, 49 (2012), 611-618. http://dx.doi.org/10.1016/j.enbuild.2012.03.007.

363 [12] C. Marinosci, G. Semprini, G.L. Morini, Experimental analysis of the summer thermal performances of a 364 naturally ventilated rainscreen façade building, Energy and Buildings, 72 (2014), 280-28.

365 http://dx.doi.org/10.1016/j.enbuild.2013.12.044.

366 [13] S. Fantucci, C. Marinosci, V. Serra, C. Carbonaro, Thermal Performance Assessment of an Opaque Ventilated 367 Façade in the Summer Period: Calibration of a Simulation Model through in-field Measurements, Energy Procedia, 111 368 (2017), 619-628, https://doi.org/10.1016/j.egypro.2017.03.224.

369 [14] A.L. Pisello, V.L. Castaldo, G. Pignatta, F. Cotana, M. Santamouris, Experimental in-lab and in-field analysis of 370 waterproof membranes for cool roof application and urban heat island mitigation, Energy and Buildings, 114 (2016) 371 180-190. http://dx.doi.org/10.1016/j.enbuild.2015.05.026.

372 [15] A. L. Pisello, Thermal-energy analysis of roof cool clay tiles for application in historic buildings and cities, 373 Sustainable Cities and Society 19 (2015), 271-280. http://dx.doi.org/10.1016/j.scs.2015.03.003.

374 [16] A. L. Pisello, V. L. Castaldo, C. Fabiani, F. Cotana, Investigation on the effect of innovative cool tiles on local 375 indoor thermal conditions: Finite element modeling and continuous monitoring, Building and Environment 97 (2016), 376 http://dx.doi.org/10.1016/j.buildenv.2015.11.038 

analysis on the thermal performance of a building roof incorporating phase change material (PCM) for thermal management, Applied Thermal Engineering, 28 (2008), 556-565, https://doi.org/10.1016/j.applthermaleng.2007.04.016.

[18] Jan Kośny, Ali Fallahi, Nitin Shukla, Elizabeth Kossecka, Ramin Ahbari, Thermal load mitigation and passive cooling in residential attics containing PCM-enhanced insulations, Solar Energy, 108 (2014), 164-177, https://doi.org/10.1016/j.solener.2014.05.007.

[19] F. Souayfanea, F. Fardouna, P.H. Biwoleb, Phase change materials (PCM) for cooling applications in buildings: A review, Energy and Buildings 129 (2016), 396-431.

[20] M. Pomianowski, P. Heiselberg, Y. Zhang, Review of thermal energy storage technologies based on PCM application in buildings, Energy and Buildings. 67 (2013), 56-69.

[21] F. Kuznik, J. Virgone, K. Johannes, In-situ study of thermal comfort enhancement in a renovated building equipped with phase change material wallboard, Renew. Energy 36 (2011), 1458-1462.

[22] X. Xu, Y. Zhang, K. Lin, H. Di, R. Yang, Modeling and simulation on the thermal performance of shapestabilized phase change material floor used in passive solar buildings, Energy Build. 37 (October (10)) (2005)10841091.

[23] C. Carbonaro, Y. Cascone, S. Fantucci, V. Serra, M. Perino, M. Dutto, Energy Assessment of A PCM-embedded Plaster: Embodied Energy Versus Operational Energy, Energy Procedia 78 (2015) 3210-3215. doi:10.1016/j.egypro.2015.11.782.

[24] S. Lu, Y. Chen, S. Liu, X. Kong, Experimental research on a novel energy efficiency roof coupled with PCM and cool materials, Energy and Buildings, 127 (2016), 159-169. http://dx.doi.org/10.1016/j.enbuild.2016.05.080. [25] A.L. Pisello, E. Fortunati, S. Mattioli, L.F. Cabeza, C. Barreneche, J.M. Kenny, F. Cotana, Innovative cool roofing membrane with integrated phase change materials: Experimental characterization of morphological, thermal and optic-energy behavior, Energy and Buildings, 112 (2016), 40-48. http://dx.doi.org/10.1016/j.enbuild.2015.11.061. [26] M. Saffari, A. de Gracia, S. Ushak, L.F. Cabeza, Economic impact of integrating PCM as passive system in buildings using Fanger comfort model, Energy and Buildings 112 (2016), 159-172. http://dx.doi.org/10.1016/j.enbuild.2015.12.006. [27] www.rubitherm.com, (Access: 04/2017).

[28] A. Komerska, L. Bianco, V. Serra, S. Fantucci, M. Rosiński, Experimental Analysis of an External Dynamic Solar Shading Integrating PCMs: First Results, Energy Procedia 78 (2015) 3452-3457. http://dx.doi.org/10.1016/j.egypro.2015.11.125.

[29] F. Goia, M. Perino M. Haase, A numerical model to evaluate the thermal behavior of PCM glazing system configurations, Energy and Buildings 54 (2012), pp. 141-153. https://doi.org/10.1016/j.enbuild.2012.07.036

[30] H. Elarga, F. Goia, A. Zarrella, A. Dal Monte, E. Benini, Thermal and electrical performance of an integrated PV-PCM system in double skin façades:A numerical study 136 (2016), 112-124. https://doi.org/10.1016/j.solener.2016.06.074 [31] V. R. Voller, An overview of numerical methods for solving phase-change, Advances in Numerical Heat Transfer 1, Taylor \& Francis, London (1996), Chapter 9.

[32] W.H. McAdams, Heat Transmission, 3rd ed., McGraw-Hill, New York, 1954.

[33] ASHRAE, 1993 ASHRAE Handbook of Fundamentals, American Society of Heating, Refrigerating and AirConditioning Engineers, Inc., Atlanta, USA, 1993. 
417 [34] I. Beausoleil-Morrison, The adaptive coupling of heat and air flow modelling within dynamic whole-building 418 simulation, Ph.D. Thesis, Energy Systems Research Unit, Department of Mechanical Engineering, University of 419 Strathclyde, Glasgow, UK, 2000.

420 [35] Y. Çengel, Heat and mass transfer: a practical approach, 2nd edition, McGraw-Hill, 2007. 


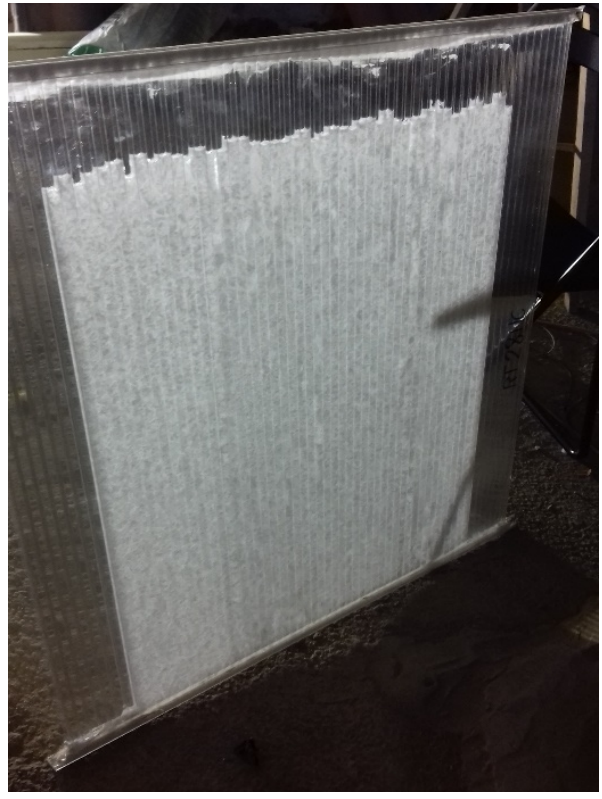

Fig.1 PCM polycarbonate layer

2

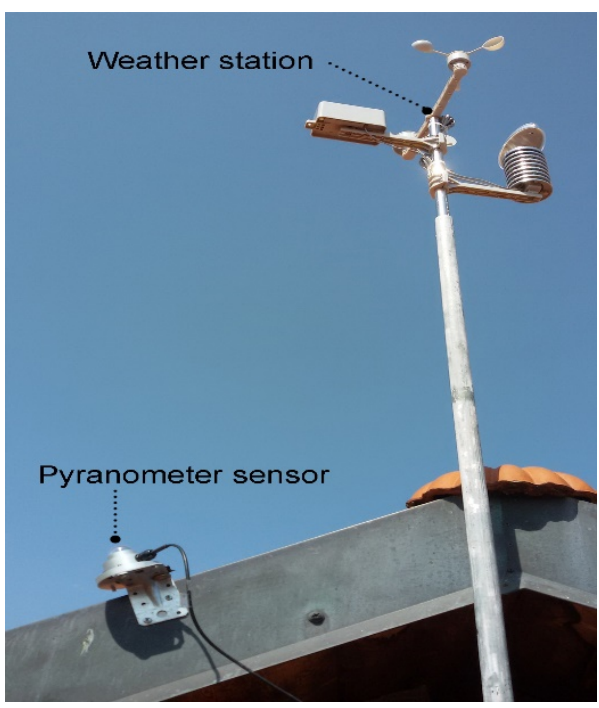

Fig.3 Weather station and pyranometer sensor

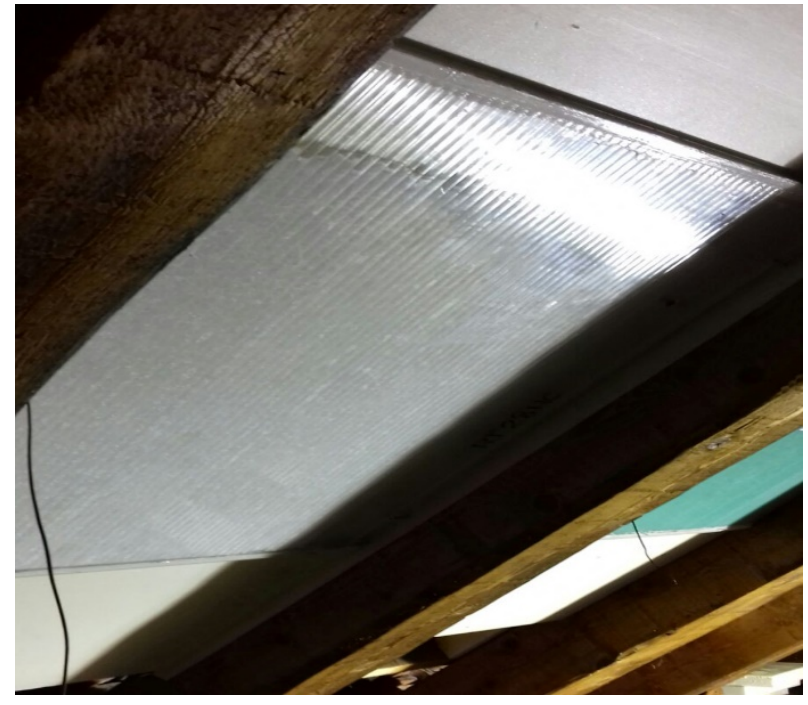

Fig.2 Installation of a PCM filled panel

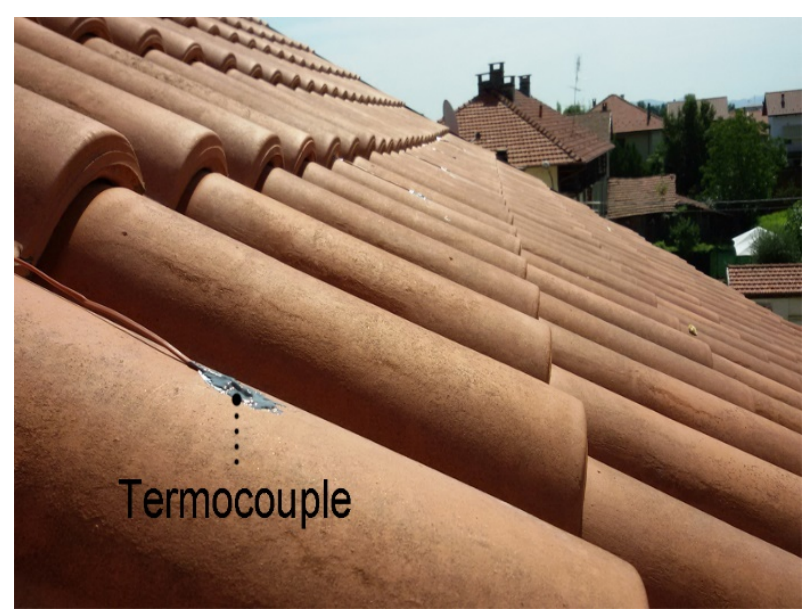

Fig. 4 Thermocouples installed above the roof tiles 


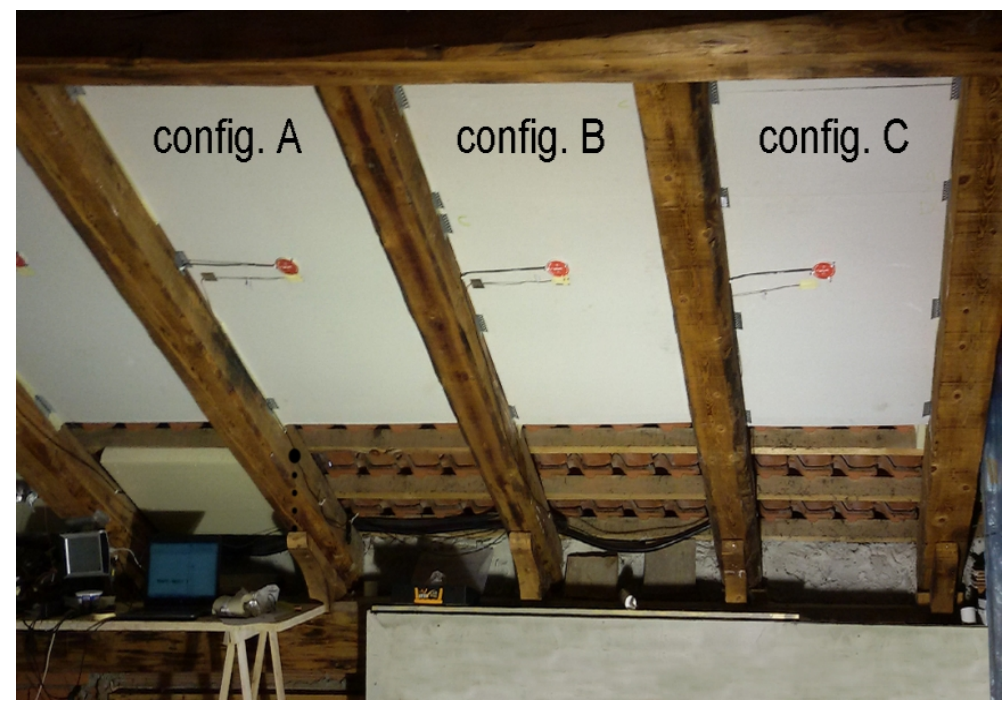

Fig. 5 From left to right, Configurations A, B and C with heat flux sensors and thermocouples placed in the indoor side

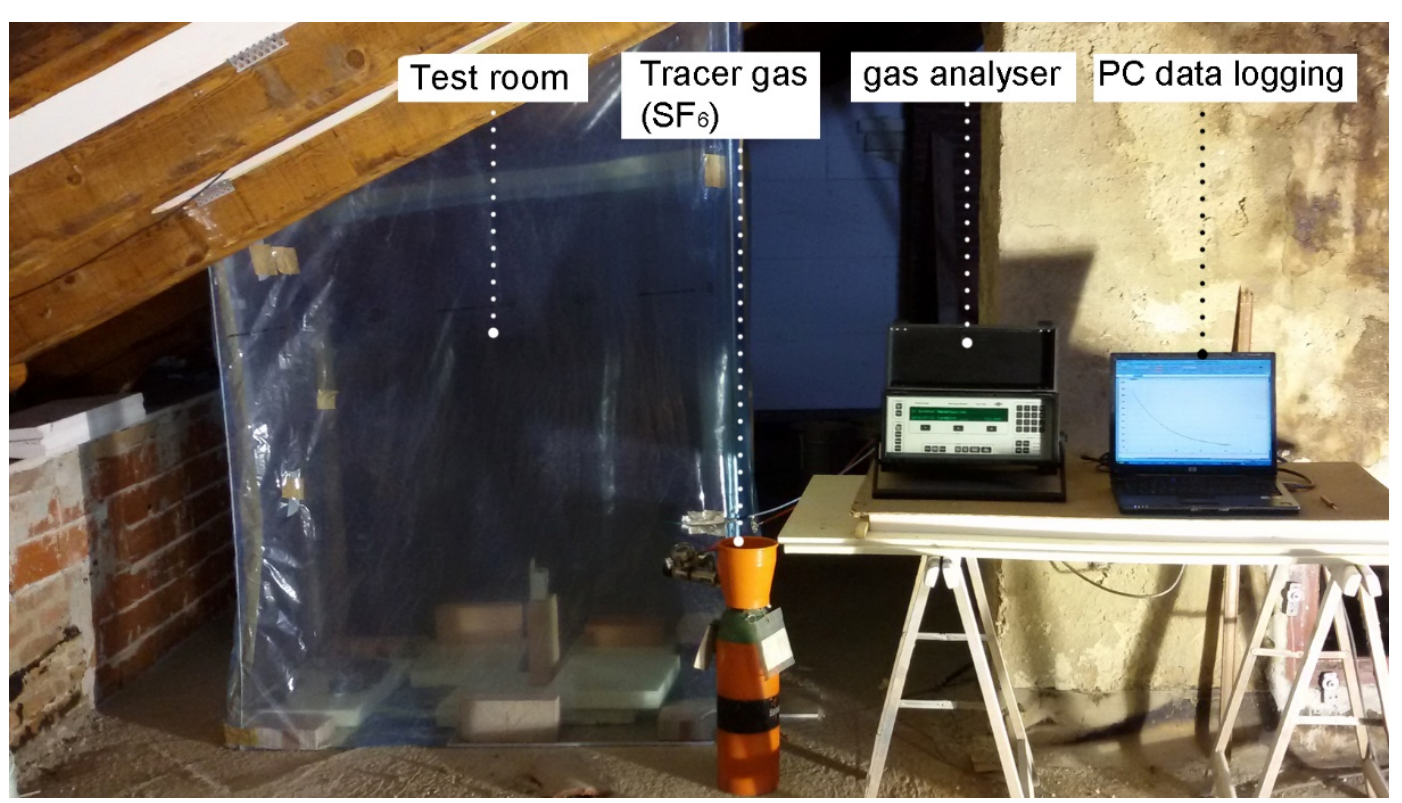

Fig. 6. Tracer gas technique used for the determination of the air infiltartion rate under the roof tiles. 


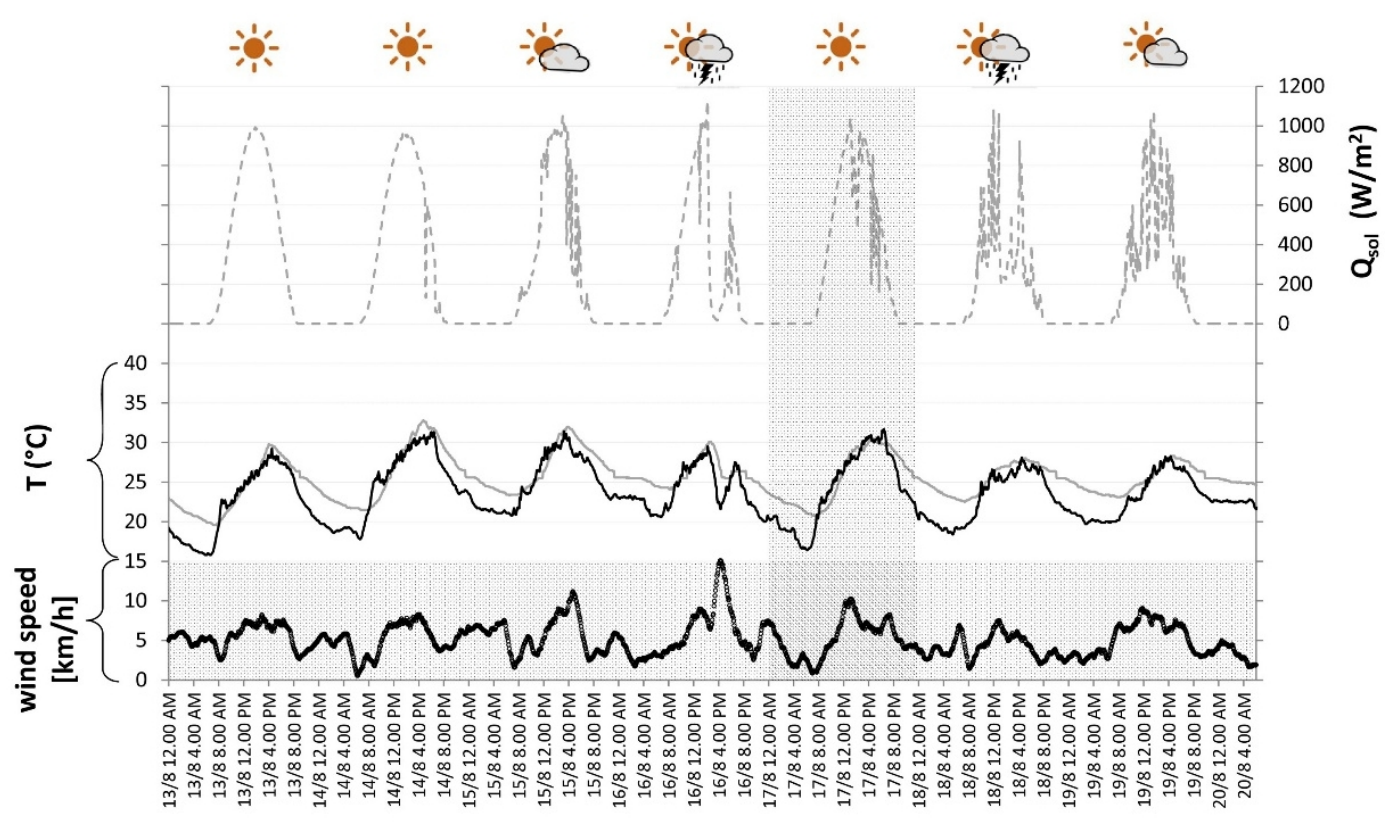

Fig. 7. Boundary conditions from $13^{\text {th }}$ to $20^{\text {th }}$ august. Incident solar radiation (dashed grey line), indoor temperature (grey line), outdoor temperature (black line) and wind speed (black dots).

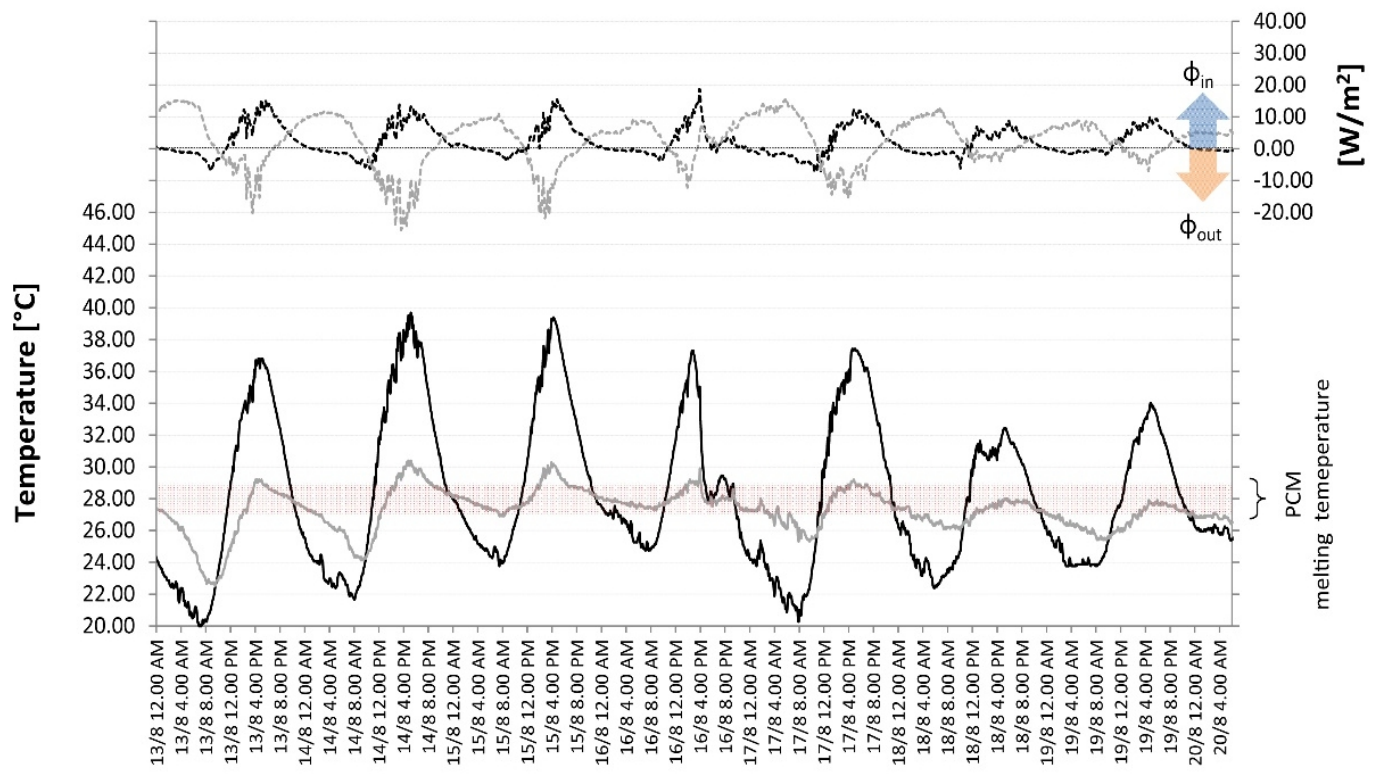

Fig. 8. Comparison between configuration A, reference roof without PCMs (black), and configuration B, roof with PCM-RT28HC (grey), heat fluxes (dashed lines) and indoor surface temperatures (continuous lines). 


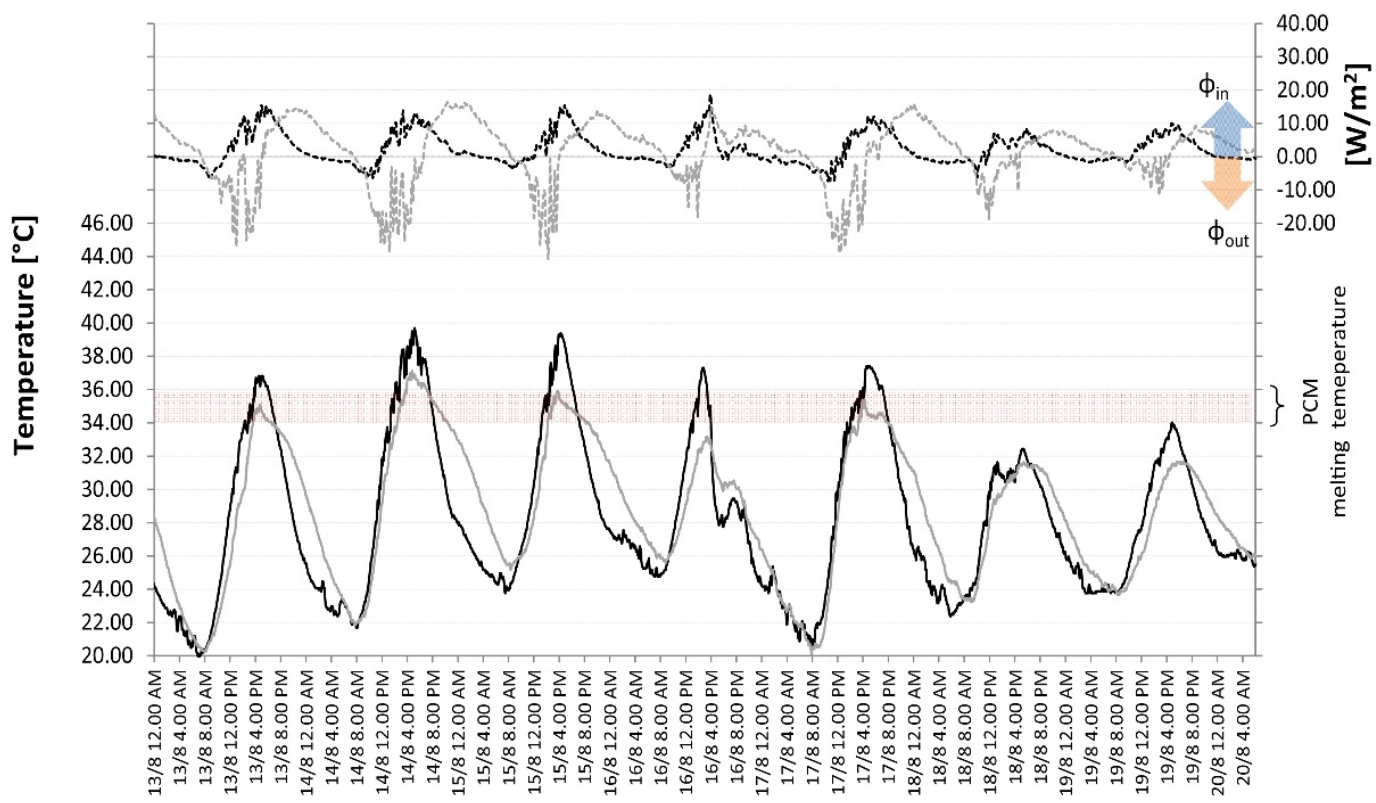

18 Fig. 9. Comparison between Configuration A, reference roof without PCMs. (black), and configuration C, roof with PCMs-RT35 (grey), heat fluxes (dashed lines) and indoor surface temperatures (continuous lines).

20

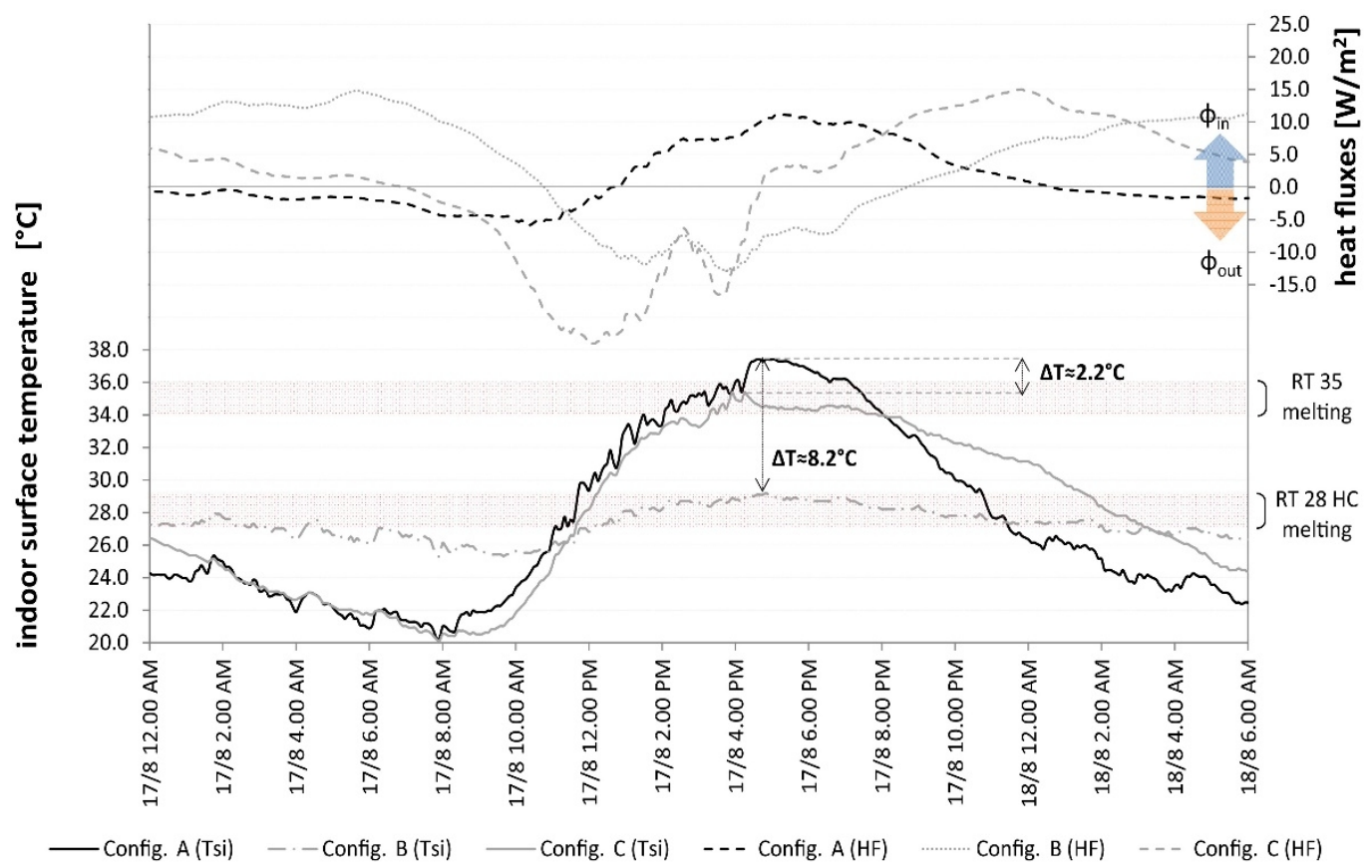

Fig. 10. Comparison between Configuration A (reference roof without PCM), B (PCM-RT28HC) and C (PCMRT35)(grey). Selected day: August 17th. 


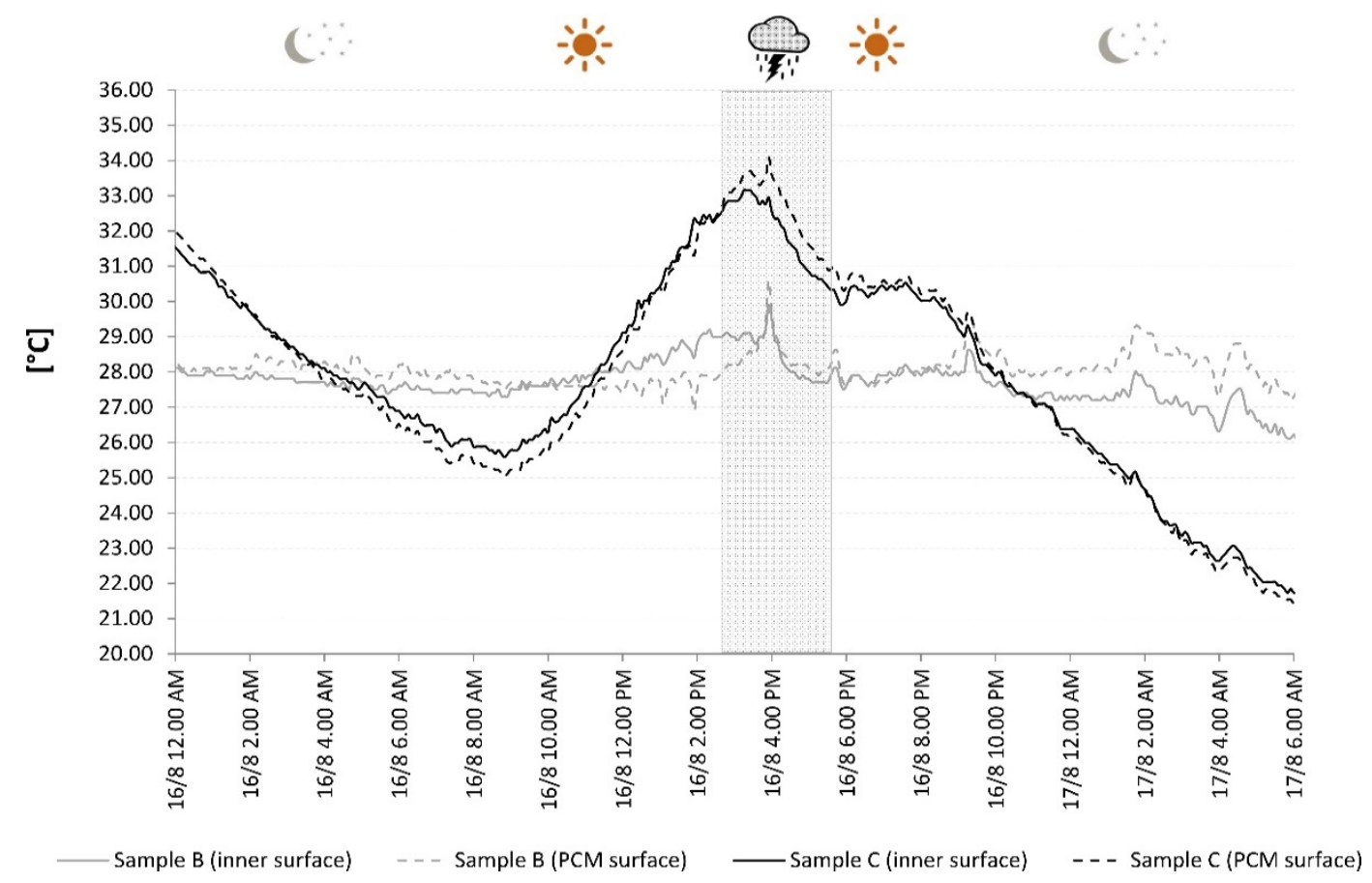

Fig. 11. Comparison between configurations B and C, PCM Surface temperature

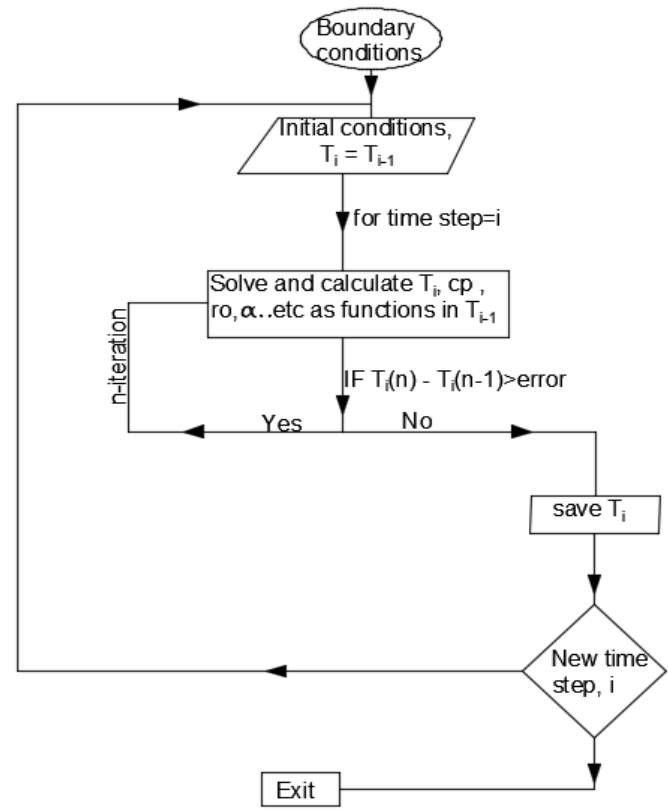

Fig. 12. Numerical code flowchart 


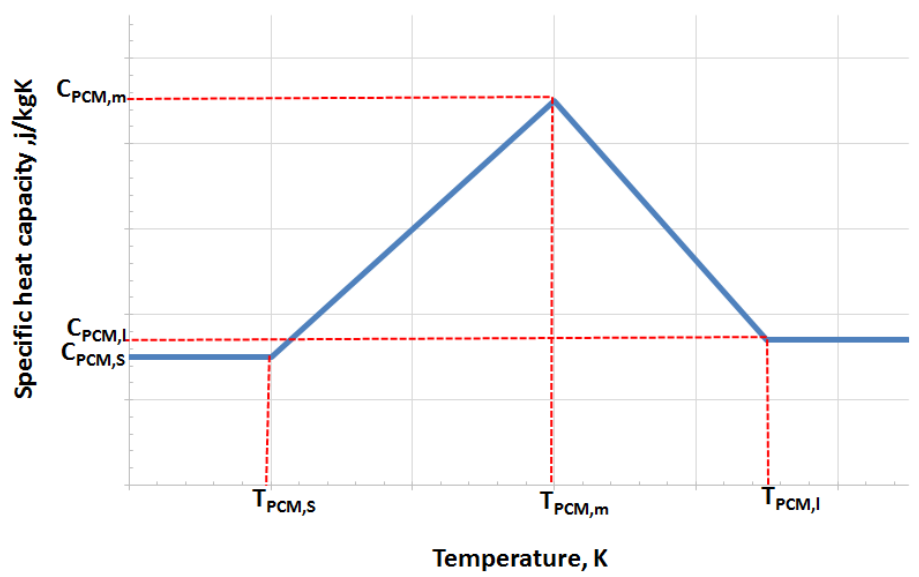

Fig. 13. Specific heat capacity as a function of PCM temperature

28

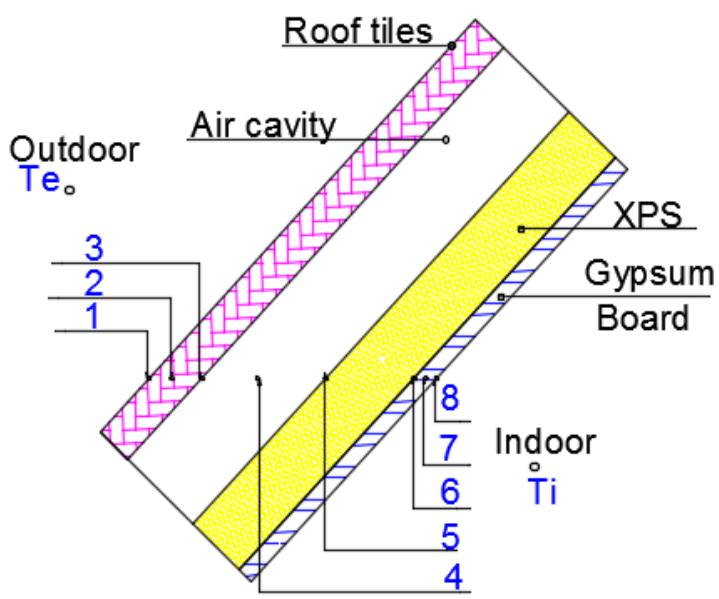

(a)

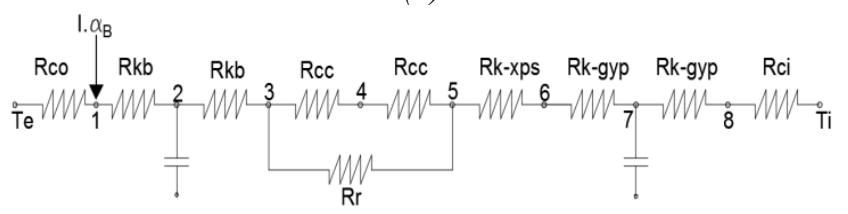

(b)

Fig. 14.(Model-A), (a) Scheme, (b) RC model 


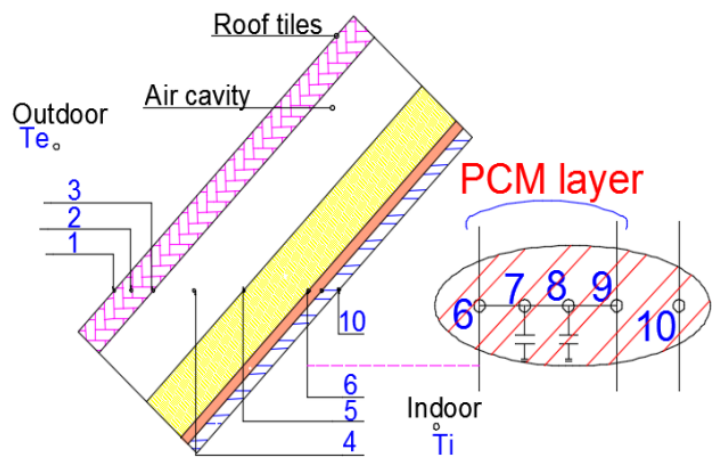

(a)

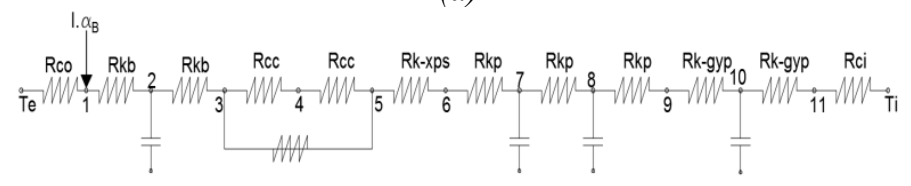

(b)

Fig. 15. (Model-B\&C), (a) Scheme, (b) RC model, PCM nodes $(7,8)$

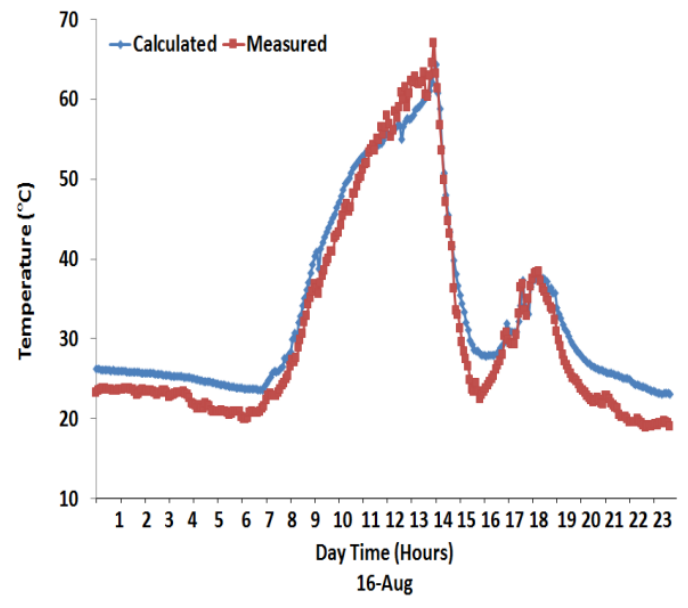

(a)

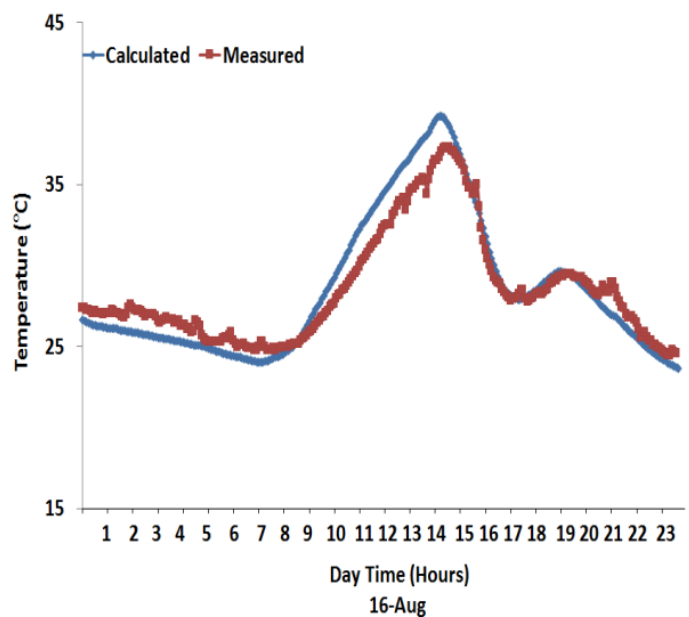

(b)

Fig. 16 Configuration A (reference config.) - Comparison between measured and predicted values. (a) outdoor surface temperature, (b) indoor surface temperature 


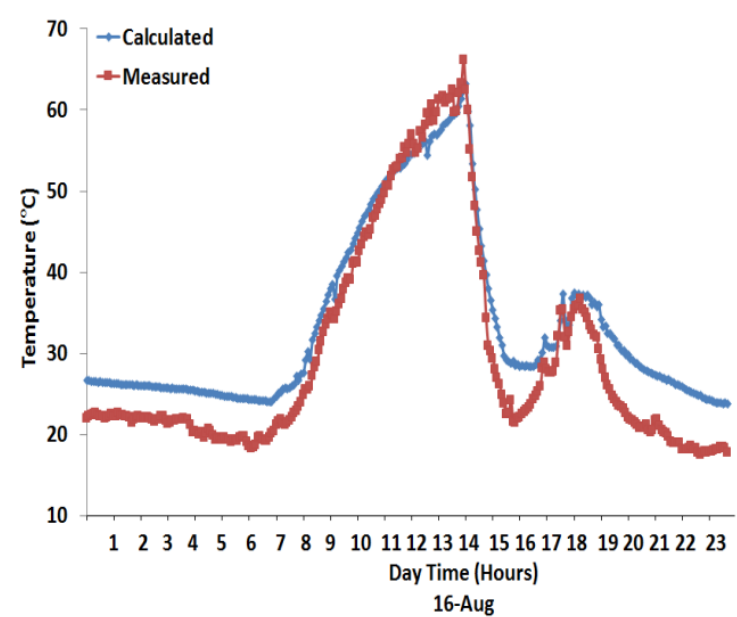

(a)

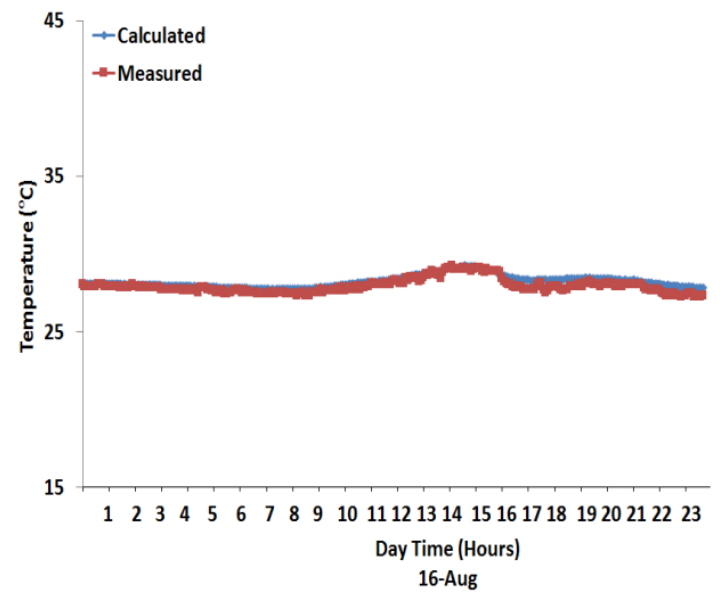

(b)

Fig. 17 Configuration B (RT28 HC) - Comparison between measured and predicted values. (a) outdoor surface temperature, (b) indoor surface temperature

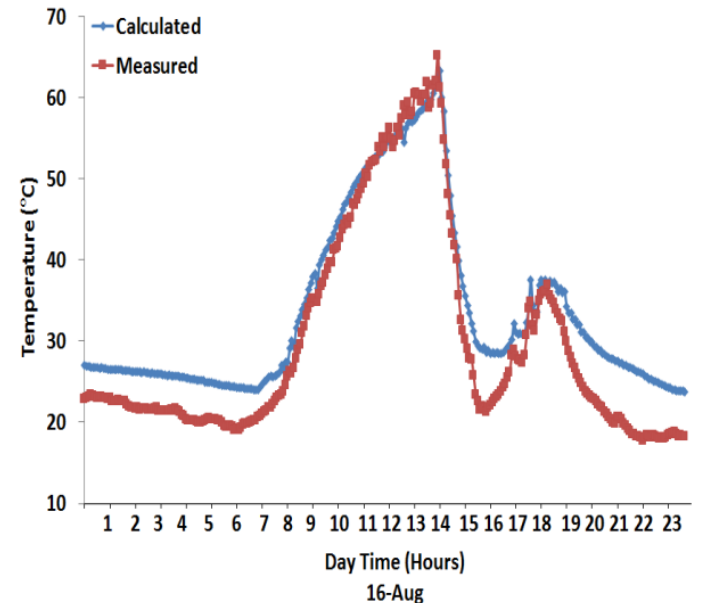

(a)

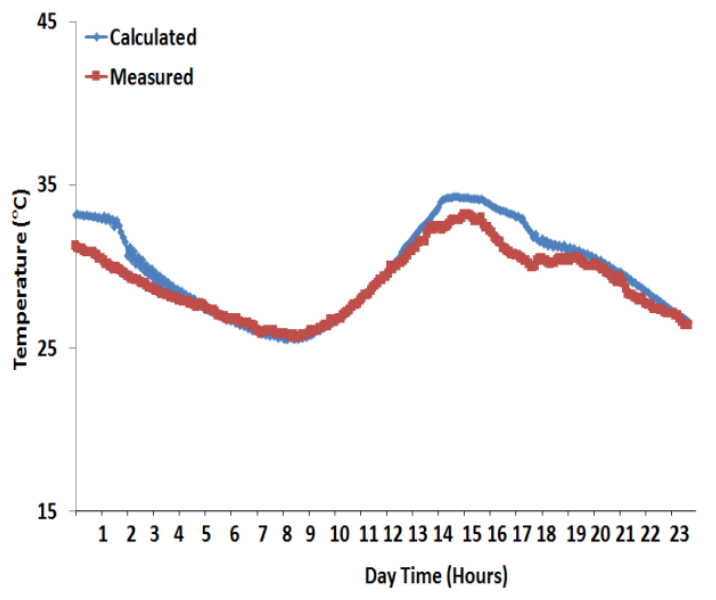

(b)

Fig. 18 Configuration C (RT35) - Comparison between measured and predicted values. (a) outdoor surface temperature, (b) indoor surface temperature 
2

Table 4. Energy loads and losses for different time intervals (August $17^{\text {th }}$ )

\begin{tabular}{|c|c|c|c|c|c|c|c|c|c|}
\hline \multirow[t]{2}{*}{ Time interval } & \multicolumn{3}{|c|}{$\begin{array}{l}\text { Configuration A } \\
\text { (reference roof no PCM) }\end{array}$} & \multicolumn{3}{|c|}{$\begin{array}{l}\text { Configuration B } \\
\text { (RT28HC-PCM) }\end{array}$} & \multicolumn{3}{|c|}{$\begin{array}{l}\text { Configuration } \mathrm{C} \\
\text { (RT35-PCM) }\end{array}$} \\
\hline & $\begin{array}{l}\text { Energy } \\
\text { losses } \\
\left(\mathrm{Wh} / \mathrm{m}^{2}\right)\end{array}$ & $\begin{array}{l}\text { Energy } \\
\text { loads } \\
\left(\mathrm{Wh} / \mathrm{m}^{2}\right)\end{array}$ & $\begin{array}{l}\text { Energy } \\
\text { balance } \\
\left(\mathrm{Wh} / \mathrm{m}^{2}\right)\end{array}$ & $\begin{array}{l}\text { Energy } \\
\text { losses } \\
\left(\mathrm{Wh} / \mathrm{m}^{2}\right)\end{array}$ & $\begin{array}{l}\text { Energy } \\
\text { loads } \\
\left(\mathrm{Wh} / \mathrm{m}^{2}\right)\end{array}$ & $\begin{array}{l}\text { Energy } \\
\text { balance } \\
\left(\mathrm{Wh} / \mathrm{m}^{2}\right)\end{array}$ & $\begin{array}{l}\text { Energy } \\
\text { losses } \\
\left(\mathrm{Wh} / \mathrm{m}^{2}\right)\end{array}$ & $\begin{array}{l}\text { Energy } \\
\text { loads } \\
\left(\mathrm{Wh} / \mathrm{m}^{2}\right)\end{array}$ & $\begin{array}{l}\text { Energy } \\
\text { balance } \\
\left(\mathrm{Wh} / \mathrm{m}^{2}\right)\end{array}$ \\
\hline 00:00 am - 8:00 am & -13.3 & - & -13.3 & - & 100.3 & 100.3 & -1.1 & 18.3 & 17.2 \\
\hline $8: 00 \mathrm{am}-12: 00 \mathrm{am}$ & -17.9 & - & -17.9 & -4.5 & 16.1 & 11.7 & -47.7 & - & -47.7 \\
\hline $12: 00 \mathrm{am}-16: 00 \mathrm{am}$ & -0.8 & 17.4 & 16.6 & -40.0 & - & -40.0 & -64.6 & - & 64.6 \\
\hline $16: 00 \mathrm{am}-20: 00 \mathrm{am}$ & - & 39.3 & 39.3 & -26.4 & - & -26.4 & -4.5 & 13.1 & 8.7 \\
\hline 20:00 am - 00:00 am & - & 16.9 & 16.9 & -0.6 & 11.1 & 10.5 & - & 49.1 & 49.1 \\
\hline
\end{tabular}

Table 1. PCM physical properties Error! Reference source not found.

\begin{tabular}{lcc}
\hline \multicolumn{1}{c}{ PCM name } & RT28 & RT35 \\
\hline Solid temperature (lower limit of phase change range) & $27^{\circ} \mathrm{C}$ & $34^{\circ} \mathrm{C}$ \\
Nominal melting temperature & $28^{\circ} \mathrm{C}$ & $35^{\circ} \mathrm{C}$ \\
Liquid temperature (upper limit of phase change range) & $29^{\circ} \mathrm{C}$ & $36^{\circ} \mathrm{C}$ \\
Specific heat Capacity $\left[\mathrm{kJ} \mathrm{kg}^{-1} \mathrm{~K}^{-1}\right]$ & 2 & 2 \\
Latent heat of fusion $\left[\mathrm{kJ} \mathrm{kg}^{-1}\right]$ & 250 & 160 \\
\hline
\end{tabular}

Table 2. Roof section: material properties. Layer 04 is included only in configurations B and C. (data retrieved from Error! Reference source not found.)

\begin{tabular}{ccccccc}
\hline Layer & Material & $\mathbf{s}$ & $\boldsymbol{\rho}$ & $\boldsymbol{\lambda}$ & $\mathbf{c p}$ & $\boldsymbol{\alpha}$ \\
& & $(\mathrm{mm})$ & $\left(\mathrm{kg} \mathrm{m}^{-3}\right)$ & $\left(\mathrm{W} \mathrm{m}^{-1} \mathrm{~K}^{-1}\right)$ & $\left(\mathrm{J} \mathrm{kg} \mathrm{k}^{-1}\right)$ & $(-)$ \\
\hline 01 & brick tiles & 30 & 1700 & 0.7 & 840 & $0.55^{*}$ \\
02 & air gap & 70 & 1.2 & N.A. & 1020 & N.A. \\
03 & XPS & 50 & 32 & 0.034 & 1500 & N.A. \\
04 & PCM & 10 & 800 & 0.14 & 2000 & N.A. \\
(config. B and C only) & gypsum board & 9.5 & 800 & 0.2 & 1000 & N.A. \\
\hline
\end{tabular}

Table 3. Peak of temperature (August1 $7^{\text {th }}$ )

\begin{tabular}{llllll}
\hline & \multicolumn{3}{c}{ peak temperature $\left({ }^{\circ} \mathrm{C}\right)$} & \multicolumn{2}{l}{ difference of Tsi $\left({ }^{\circ} \mathrm{C}\right)$} \\
\cline { 2 - 6 } Configuration & A & B & C & B vs A & C vs A \\
\hline $\mathrm{T}_{\mathrm{si}, \max (12 \mathrm{am}-00 \mathrm{pm})}$ & 37.3 & 29.1 & 35.2 & 8.2 & 2.1 \\
$\mathrm{~T}_{\mathrm{si}, \min (00 \mathrm{pm}-12 \mathrm{am})}$ & 20.2 & 25.4 & 20.2 & 5.2 & 0.0 \\
\hline
\end{tabular}


18 Table 5. RMSE for each nodes, $T_{1}$ is the outdoor surface temperature, $T_{10}$ is the indoor surface temperature, except for configuration $\mathrm{A}$ in which $\mathrm{T}_{8}$ correspond to the inner layer.

\begin{tabular}{|c|c|c|c|}
\hline node & Config. A & Config. B & Config. C \\
\hline $\mathrm{T}_{1}$ & $3.4^{\circ} \mathrm{C}$ & $3.8^{\circ} \mathrm{C}$ & $4.0^{\circ} \mathrm{C}$ \\
\hline $\mathrm{T}_{3}$ & $3.2^{\circ} \mathrm{C}$ & $3.5^{\circ} \mathrm{C}$ & $4.0^{\circ} \mathrm{C}$ \\
\hline $\mathrm{T}_{4}$ & $3.3^{\circ} \mathrm{C}$ & $3.2^{\circ} \mathrm{C}$ & $3.8^{\circ} \mathrm{C}$ \\
\hline $\mathrm{T}_{5}$ & $3.5^{\circ} \mathrm{C}$ & $3.5^{\circ} \mathrm{C}$ & $3.2^{\circ} \mathrm{C}$ \\
\hline $\mathrm{T}_{6}$ & $1.2^{\circ} \mathrm{C}$ & $0.5^{\circ} \mathrm{C}$ & $0.5^{\circ} \mathrm{C}$ \\
\hline $\mathrm{T}_{8}$ & $1.9^{\circ} \mathrm{C}$ & $\mathrm{n} / \mathrm{a}$ & $\mathrm{n} / \mathrm{a}$ \\
\hline $\mathrm{T}_{9}$ & $\mathrm{n} / \mathrm{a}$ & $0.5^{\circ} \mathrm{C}$ & $0.5^{\circ} \mathrm{C}$ \\
\hline $\mathrm{T}_{10}$ & $\mathrm{n} / \mathrm{a}$ & $0.4^{\circ} \mathrm{C}$ & $0.4^{\circ} \mathrm{C}$ \\
\hline
\end{tabular}

20 